\title{
Decreases in average bacterial community rRNA operon copy number during succession
}

\author{
Diana R Nemergut ${ }^{1,2}$, Joseph E Knelman ${ }^{2,3}$, Scott Ferrenberg ${ }^{3,4}$, Teresa Bilinski ${ }^{5}$, \\ Brett Melbourne $^{3}$, Lin Jiang ${ }^{6}$, Cyrille Violle ${ }^{7}$, John L Darcy ${ }^{3}$, Tiffany Prest ${ }^{1}$, \\ Steven K Schmidt ${ }^{3}$ and Alan R Townsend ${ }^{8}$ \\ ${ }^{1}$ Department of Biology, Duke University, Durham, NC, USA; ${ }^{2}$ Institute of Arctic and Alpine Research, \\ University of Colorado, Boulder, CO, USA; ${ }^{3}$ Department of Ecology and Evolutionary Biology, University of \\ Colorado, Boulder, CO, USA; ${ }^{4}$ U.S. Geological Survey, Canyonlands Research Station, Moab, UT, USA; \\ ${ }^{5}$ Department of Biological Sciences, St Edward's University, Austin, TX, USA; ${ }^{6}$ School of Biology, Georgia \\ Institute of Technology, Atlanta, GA, USA; ${ }^{7}$ Centre d'Ecologie Fonctionnelle et Evolutive, Montpellier, France \\ and ${ }^{8}$ Nicholas School of the Environment, Duke University, Durham, NC, USA
}

\begin{abstract}
Trait-based studies can help clarify the mechanisms driving patterns of microbial community assembly and coexistence. Here, we use a trait-based approach to explore the importance of rRNA operon copy number in microbial succession, building on prior evidence that organisms with higher copy numbers respond more rapidly to nutrient inputs. We set flasks of heterotrophic media into the environment and examined bacterial community assembly at seven time points. Communities were arrayed along a geographic gradient to introduce stochasticity via dispersal processes and were analyzed using 16 S rRNA gene pyrosequencing, and rRNA operon copy number was modeled using ancestral trait reconstruction. We found that taxonomic composition was similar between communities at the beginning of the experiment and then diverged through time; as well, phylogenetic clustering within communities decreased over time. The average rRNA operon copy number decreased over the experiment, and variance in rRNA operon copy number was lowest both early and late in succession. We then analyzed bacterial community data from other soil and sediment primary and secondary successional sequences from three markedly different ecosystem types. Our results demonstrate that decreases in average copy number are a consistent feature of communities across various drivers of ecological succession. Importantly, our work supports the scaling of the copy number trait over multiple levels of biological organization, ranging from cells to populations and communities, with implications for both microbial ecology and evolution.

The ISME Journal (2016) 10, 1147-1156; doi:10.1038/ismej.2015.191; published online 13 November 2015
\end{abstract}

\section{Introduction}

A broader understanding of the forces guiding microbial community assembly is important for predictions about the effects of environmental change on microbially mediated ecosystem processes (Hanson et al., 2012; Nemergut et al., 2013). Several studies have documented the roles of species sorting (Langenheder and Székely, 2011; Evans and Wallenstein, 2014), competition (Goberna et al., 2014; Koeppel and $\mathrm{Wu}, 2014)$, priority effects (Fukami et al., 2010; Andersson et al., 2014), dispersal (Langenheder et al., 2012; Lindström and Langenheder, 2012) and ecological drift (Ofiteru et al., 2010; Stegen et al., 2012, 2013) in microbial

Correspondence: J Knelman, Department of Ecology and Evolutionary Biology, University of Colorado, Campus Box 334, Boulder, CO 80309, USA.

E-mail: joseph.knelman@colorado.edu

Received 15 February 2015; revised 27 July 2015; accepted 25 September 2015; published online 13 November 2015 community assembly. Further, several studies have shown that the relative importance of these different assembly processes changes with nutrient status (Langenheder et al., 2012; Knelman et al., 2014), disturbance (Ferrenberg et al., 2013) and successional processes (Zhou et al., 2014). Also, the relative importance of assembly processes may vary between different fractions of the community based on ecological strategies and/or relative abundance (Langenheder and Székely, 2011). However, we lack a comprehensive, theoretical understanding of why different microbial assembly processes vary in time and space. One key step toward developing a more mechanistic appreciation of microbial community assembly is to understand the role of functional traits in community assembly (Violle et al., 2007; Green et al., 2008).

Trait-based approaches may greatly inform microbial ecology given how they have advanced our understanding of plant community assembly by providing hypotheses for mechanisms of assembly that apply across ecosystems (Garnier et al., 2004; 
Ackerly and Cornwell, 2007; Kraft et al., 2007; Webb et al., 2010). For example, Shipley et al. (2006) used a statistical approach to identify eight plant traits important for plant community assembly processes, which explained 94\% of variation in plant community composition across a successional sere. Likewise, microorganisms exhibit variation in a variety of key traits that may scale from individuals to communities (Fierer et al., 2014; Goberna et al., 2014), some of which may correlate with distribution patterns (Fierer et al., 2007; Lennon et al., 2012). Indeed, trait-based approaches may be especially important to apply to microbial systems to make sense of assembly mechanisms in light of high levels of biodiversity, horizontal gene transfer and redundancy, which may otherwise complicate taxonomic and/or phylogenetic approaches (Krause et al., 2014).

One trait that may be important in heterotrophic bacterial community assembly is rRNA operon copy number (Klappenbach et al., 2000; Shrestha et al., 2007; Yano et al., 2013). rRNA operon number varies over an order of magnitude between different bacterial species (Klappenbach et al., 2001) and has been correlated with rates and efficiencies of a variety of cellular processes including growth rate, lag time, sporulation efficiency, motility and competence (Condon et al., 1995; Klappenbach et al., 2000; Stevenson and Schmidt, 2004; Yano et al., 2013; Lauro et al., 2009). In general, rRNA operon copy number correlates positively with attributes that could be classified as 'r-selected' (sensu Reznick et al., 2002), and genetic studies have revealed the importance of rRNA copy number on microbial physiology under conditions of increasing nutrients (Stevenson and Schmidt, 2004; Lauro et al., 2009).

As variation in nutrient supply is often a characteristic of successional sequences, and the importance of life history characteristics have long been described in plant community successional theory (Grime, 1977; Matthews, 1992; Chapin et al., 1994; Walker and del Moral, 2003), here we ask if rRNA operon copy number varies in a predictable pattern in microbial community assembly across succession. We placed microcosms of sterile laboratory media out into the environment and examined bacterial community composition and rRNA operon copy number as a community aggregated trait (Garnier et al., 2007; Fierer et al., 2014) at seven time points during the first $99 \mathrm{~h}$ of community development. We hypothesized that the average rRNA operon copy number would be high in earlier communities and would decrease throughout succession. We further tested this hypothesis by analyzing bacterial community data from other soil and sediment successional sequences from markedly different environments. Our results suggest that decreases in average rRNA operon copy number are a consistent feature of communities across multiple ecosystem types.

\section{Materials and methods}

We arrayed microcosms of heterotrophic media along a $15-\mathrm{km}$ transect beneath the understory of a tropical coastal forest on the Yucatan Peninsula, Mexico (climate data available here: http://www. worldclim.org/). We added $100 \mathrm{ml}$ of autoclaved, filter-sterilized nutrient broth (Difco Laboratories, Detroit, MI, USA) containing $10 \mathrm{mg} \mathrm{ml}^{-1}$ cycloheximide (Sigma-Aldrich, St Louis, MO, USA) as a eukaryotic inhibitor to sterile Mason jars covered with a fine (1 mm mesh) screen. To investigate the role of stochasticity via dispersal, duplicate microcosms (Mason jars) were arrayed along the transect in locations that were at least $1 \mathrm{~km}$ apart (Supplementary Figure 1A). At 3, 19, 23.5, 27.5, 43.5, 51.5, 67 and $99 \mathrm{~h}$, microcosms were sampled $(4 \mathrm{ml})$ after stirring the media with a sterile pipet.

Half of each sample was used to measure optical density at $595 \mathrm{~nm}$ while the other half was preserved at $-20^{\circ} \mathrm{C}$ for DNA extraction using the UltraClean Microbial DNA (MO BIO Laboratories, Carlsbad, CA, USA) kit. We amplified $16 \mathrm{~S}$ rRNA genes for pyrosequencing using the primers and conditions described in Fierer et al. (2008) and Knelman et al. (2012); none of the samples taken at $3 \mathrm{~h}$ yielded PCR products that were visible on an agarose gel and these samples were thus discarded from the study. As well, the sterility of microcosm 9B (all time points) and of sample $8 \mathrm{~B}$ at time point 5 were compromised and these samples were discarded from future analyses. Pyrosequencing was performed by Engencore (University of South Carolina).

Pyrosequencing data were screened using the QIIME toolkit (Caporaso et al., 2010) with the following parameters: quality score $>25$, sequence length $>200$ and $<400$, maximum homopolymer of 6, 0 maximum ambiguous bases, and 0 mismatched bases in the primer. First, operational taxonomic units (OTUs) were picked at the 97\% identity level using UCLUST (Edgar, 2010) in QIIME with the default settings and data were denoised using Denoiser (Reeder and Knight, 2010). OTUs were randomly subsampled in QIIME such that each library contained 608 sequences, the fewest sequences in a single sample. In addition, OTUs were selected using the closed reference command in QIIME against the gg_13_5otus representative set at the $97 \%$ identity level (DeSantis et al., 2006) for phylogenetic identification and copy number estimation. We then used the web-based implementation of PICRUSt (Phylogenetic Investigation of Communities by Reconstruction of Unobserved States, Langille et al., 2013) to estimate rRNA operon copy number. OTU data were then normalized (standardized) for copy number by dividing by copy number. For each sample, we calculated the community aggregated trait value (weighted mean) by taking the product of the estimated operon copy number and the relative abundance for each OTU, and summing this value across all OTUs in a 
sample. Operon copy number variance was similarly calculated as a weighted variance.

We found a strong correlation between standardized and nonstandardized data as well as between UniFrac, a phylogeny-based beta diversity metric (Lozupone et al., 2006), and Bray-Curtis dissimilarity, an OTUbased beta diversity metric (Mantel tests on pairwise dissimilarity matrices all had correlations $>0.8$ and were all significant at $P<0.001$ ). We chose to perform all subsequent analyses on the Bray-Curtis dissimilarities of standardized data because of our focus on individual taxa. We also supplemented these analyses with an analysis of phylogenetic clustering (Webb et al., 2008; see below). We used the vegan package (Oksanen et al., 2013) in $\mathrm{R}$ ( $\mathrm{R}$ Development Core Team, 2013) to generate an ordination plot for visualization of community shifts. The best solution, as determined by the lowest stress and visual examination of stress plots, was found by performing NMDS on square-root transformed Bray-Curtis dissimilarity.

To examine changes in taxonomic community structure based on the Bray-Curtis dissimilarity matrix, we performed an analysis of multivariate homogeneity of group dispersions (Anderson, 2006) to test for changes in community composition over time and used permutational multivariate analysis of variance (PERMANOVA, Anderson, 2001) to test for changes in beta diversity over time. These analyses were conducted in QIIME using the PERMANOVA function and PERMDISP function (which in turn uses the betadisper function of the vegan package in R). We calculated the nearest taxon and net relatedness indices (NTI and NRI, respectively (Webb, 2000)) for each time point using the ses. mpd and the ses.mntd functions in the picante package in $\mathrm{R}$ and multiplying values by -1 (Kembel et al., 2010). For this analysis, we used the filter_tree command in QIIME to trim the gg_13_5 Greengenes tree to contain only OTUs that were observed in this study. We used ANOVA and Kruskal-Wallis post hoc tests (pgirmess package) in $\mathrm{R}$ to determine differences in community aggregated trait values for rRNA copy number, NTI and NRI across time. Finally, we generated frequencyabundance plots for successional time points $23.5 \mathrm{~h}$ and onwards $(19 \mathrm{~h}$ showed nondistinguishable patterns from the $23.5 \mathrm{~h}$ time point) and implemented the Sloan et al. (2006) neutral community model to determine if frequency-abundance patterns were indicative of neutral assembly.

We also examined three additional data sets relating to primary and secondary successional sequences: a salt marsh sediment (Dini-Andreote et al., 2015), a recently deglaciated soil from the Toklat glacier in Alaska, and a burned forest soil from the Four Mile Canyon Fire outside of Boulder, CO (Ferrenberg et al., 2013). Soils from the Toklat glacier were sampled in July of 2014. Samples were collected from frost-heave mounds along the glacial chronosequence by collecting the top $2 \mathrm{~cm}$ of material. Samples were frozen upon removal from the field and shipped to the University of Colorado at Boulder and kept at $-80^{\circ} \mathrm{C}$ until processing. DNA was extracted from each sample using the MO BIO PowerSoil DNA extraction kit (MO BIO Laboratories). The $16 \mathrm{~S}$ rRNA gene was amplified using the primer set $515 \mathrm{~F} / 806 \mathrm{R}$ (Caporaso et al., 2012) and sequenced on the Illumina MiSeq platform (Illumina Inc., San Diego, CA, USA) using paired-end 2x150 bp chemistry. A 30\% phiX spike was added to the run to compensate for otherwise limited amplicon variability (Caporaso et al., 2012). Paired-end reads were demultiplexed and assembled using QIIME (Caporaso et al., 2010).

Soils from the Four Mile Canyon burn site were sampled and sequenced as described in Ferrenberg et al. (2013): 10 soil samples from 29 months after the burn were compared with samples from 4 months after the burn. These data sets were analyzed for rRNA operon copy number according to the workflow previously described. Statistical differences between successional categories were examined using nonparametric Kruskal-Wallis ANOVA (pgirmess package). The Toklat glacier forefield data set was divided into the unvegetated and vegetated chronosequence for this categorical analysis and a linear regression model on the natural log transformed response variable was also performed.

All sequence data have been archived and are publically available at the doi:10.6084/m9. figshare.1556152.

\section{Results and Discussion}

Most bacterial communities grew to stationary phase (Supplementary Figure 2) over the course of the experiment. Early communities were dominated by organisms related to Bacillus (Supplementary Figure 3). Later successional communities showed increases in the relative abundance of organisms related to the Enterobacteriales and Pseudomonadales and significantly changed in taxonomic composition over time (PERMANOVA, $P=0.001$ ). Beta diversity in early successional communities was low: NMDS plots showed that communities clustered together and were characterized by low levels of taxonomic dispersion (Figures 1a and b). After $43 \mathrm{~h}$, beta diversity was significantly higher than in the early successional communities (PERMDISP contrasts, $P=0.001$ ) and remained high until the end of the experiment (Figure 1b). These results contrast with those of Bell (2010) who found that air-seeded heterotrophic microbial communities converged through time. This may be due to the richer media used in the present study, which could change the relative roles of stochasticity and determinism in community assembly (Keddy et al., 1997; Chase, 2003, 2010; Kardol et al., 2013), and/or due to the differences in the time scales of the studies (99h vs 28 days). 
a

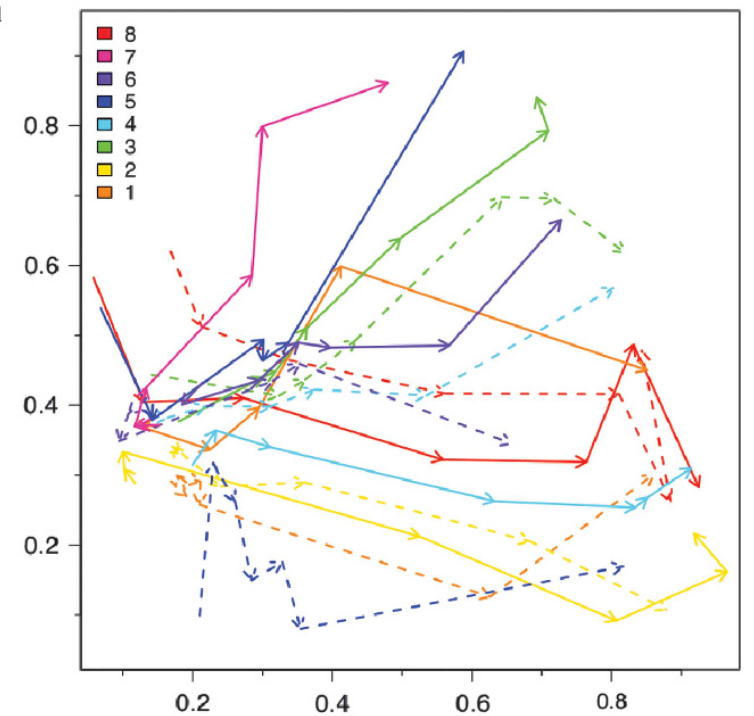

b

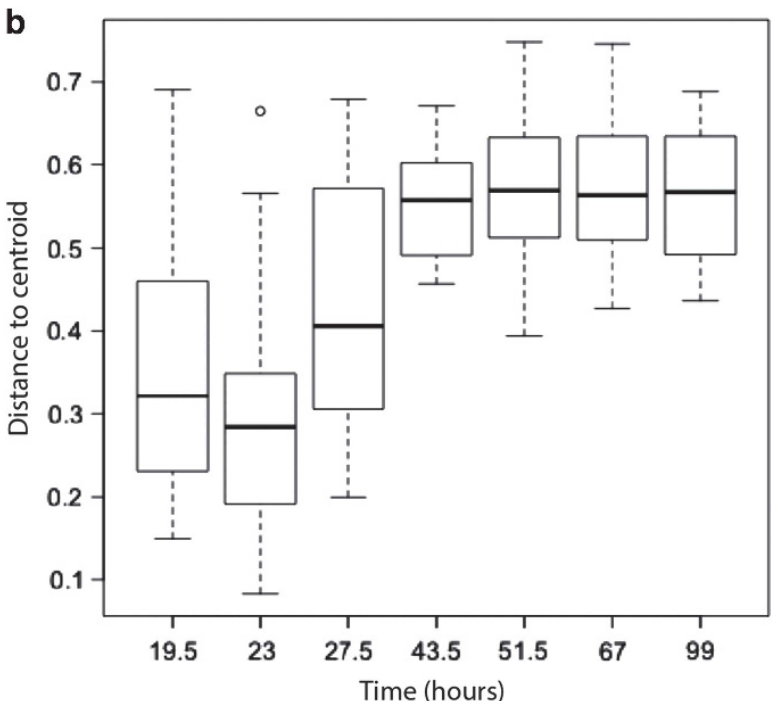

Figure 1 (a) NMDS plot showing an increase in beta diversity over successional time. Different colors represent different microcosms from distinct geographic distances (see Supplementary Figure 1); hatched lines of the same color represent replicate microcosms. Points are joined to show successional trajectories over the course of the experiment; terminal arrows show the community composition in the microcosms at the end of the experiment. The scale represents relative Bray-Curtis dissimilarity values. (b) Boxplot showing an increase in beta diversity through successional time. The plot displays Bray-Curtis dissimilarity of each replicate to the centroid (a measure of beta diversity) for each time point. PERMDISP analysis demonstrates significant increases in beta diversity (measured as multivariate dispersion), with samples after $43 \mathrm{~h}$ being significantly more dispersed than earlier time points (PERMDISP, $P=0.001$ ).

Mean community aggregated rRNA operon copy number started out high across samples, at more than nine copies (Figure 2). By the end of the experiment, the mean community aggregated copy number had declined to an average of 3.6 copies, significantly lower than the first three successional time points (19-27.5 h; Kruskal-Wallis contrasts $P<0.05$; Supplementary Table 1). Variance in copy number was lowest at the beginning and the end of

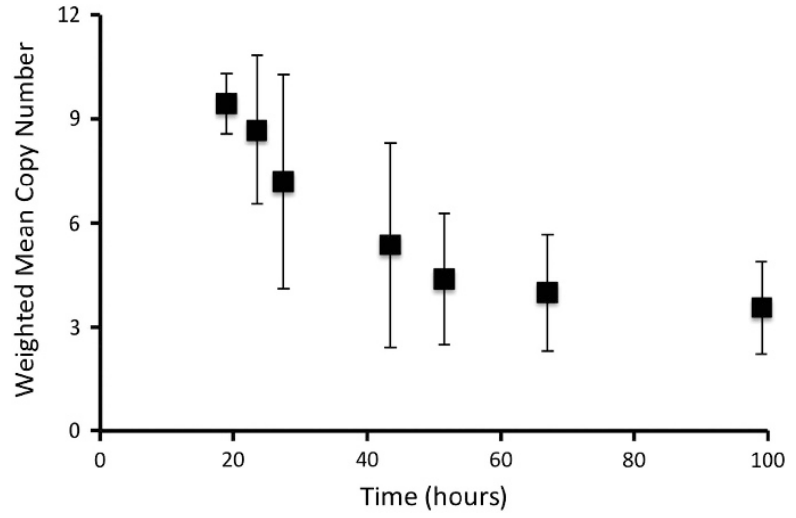

Figure 2 Scatterplot showing a decrease in the mean weighted rRNA copy number over successional time as well as lower variance in copy number in both early and late communities. Copy number was estimated using PICRUSt (Langille et al., 2013) and weighted values were obtained by multiplying copy numbers by relative abundance for each OTU and taking the summation of these values for each community. Bars represent s.d.

the experiment and was highest between 23.5 and $43.5 \mathrm{~h}$. Analysis of copy number trends within individual flasks showed that this variance appeared to be largely driven by differences in the timing of a decrease in mean aggregated copy number, and while most communities showed consistent decreases in copy number through time, this variance was the result of asynchronous decreases rather than stochastic fluctuations. Average copy number therefore appears to be a community-level trait (Fierer et al., 2014) that serves as an indicator for ecological history. For example, recently DeAngelis et al. (2015) demonstrated that soil warming significantly decreased average rRNA copy number, possibly reflecting shifts in microbial substrate availability and thus growth dynamics.

Frequency-abundance plots (Sloan et al., 2006) revealed that the most locally abundant and widely distributed organisms across samples had high average operon copy number at the beginning of the experiment but that there was a marked transition toward organisms with lower copy numbers that are less widely distributed through successional time (Figure 3). Thus, together, our results support a simultaneous divergence in community composition and a convergence in mean aggregated rRNA operon copy during microbial succession.

Similar patterns of trait convergence have been observed for other microbial communities and for plant communities (Fukami et al., 2005; Burke et al., 2011), and the patterns that we observed here allow us to generate more mechanistic hypotheses about the importance of different assembly mechanisms in this experimental system. In other studies, the importance of stochastic assembly processes has been proposed in early microbial succession based on deviation from null models (Ferrenberg et al., 2013; Zhou et al., 2014) and based on the analysis of more controlled microcosm manipulations (Langenheder and Székely, 2011). Likewise, here our data show that early community 

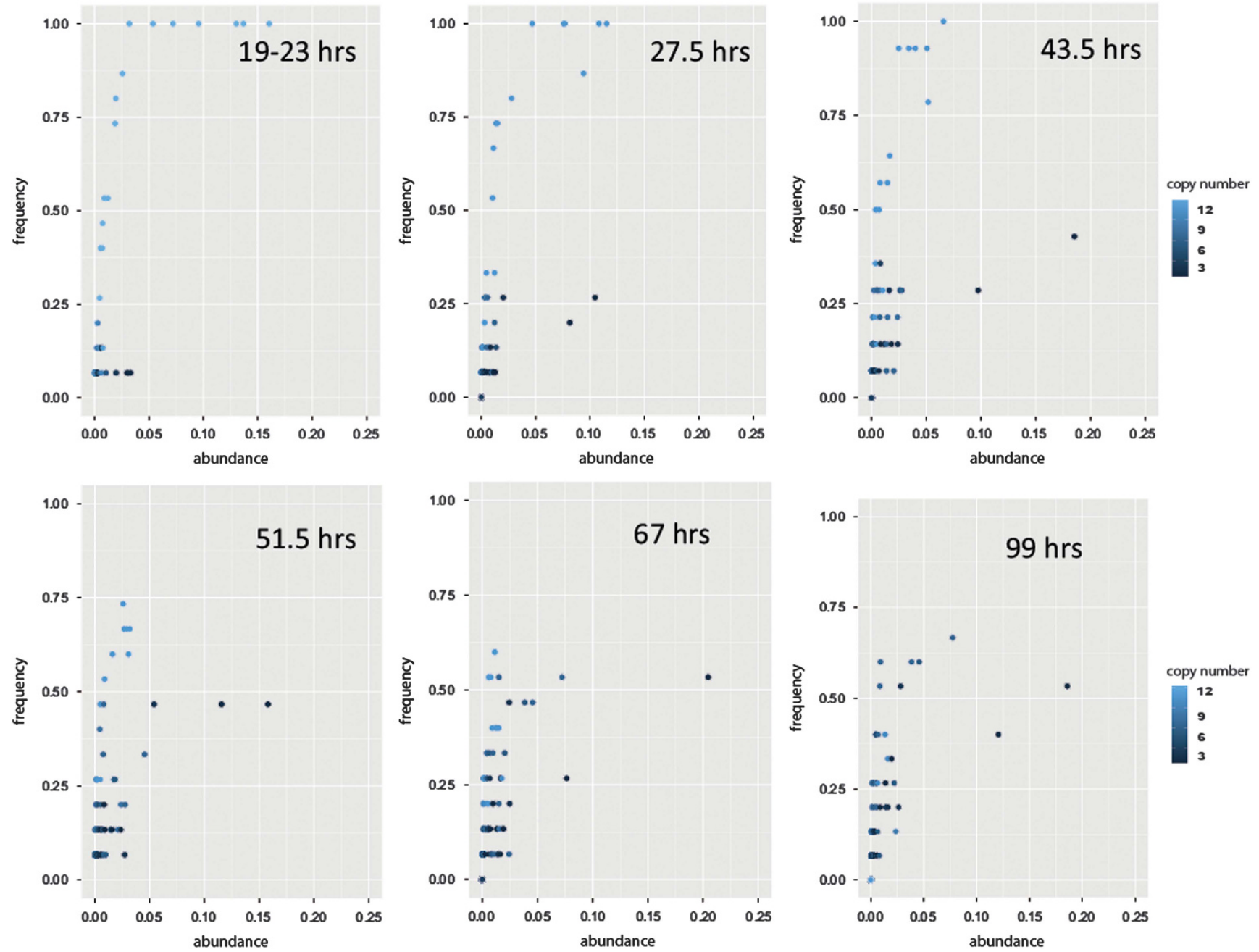

Figure 3 Frequency-abundance plots over successional time that show an increase in the relative importance of taxa with lower rRNA copy numbers. The plots at both 19 and $23 \mathrm{~h}$ were similar so only the 23 -h plot is shown. Each point represents a unique OTU and we have plotted its average relative abundance within a community against its frequency (distribution across samples) among communities. Points are colored by the rRNA copy number as estimated using PICRUSt (Langille et al., 2013).

composition conforms to frequency-abundance relationships that would be expected under neutral processes (Figure 3), with data from the first two time points fitting the Sloan et al. (2006) neutral community model $\left(\mathrm{N}_{\mathrm{T}} \mathrm{m}=5.3\right.$ and 5.9 for 19 and $27.5 \mathrm{~h}$, respectively), while data from later time points do not.

Yet, this study is important in demonstrating that while the observed taxonomic distribution relationships may reflect stochasticity in the assembly of organisms present within the early successional communities, there is low variance in the mean aggregated rRNA operon copy number in early successional communities (Figure 2). Thus, organisms with high operon copy number may have a selective advantage at the first time points, likely because of their ability to respond rapidly to nutrient inputs (Klappenbach et al., 2000; Yano et al., 2013) and/or because of their ability to form spores (Yano et al., 2013). At the same time, these organisms may not experience significant competition pressure because of combined high nutrient/low biomass levels in early succession. Indeed, calculations of the NRI and NTI, respectively (Webb, 2000; Webb et al., 2008) reveal phylogenetic clustering of early successional communities and a significant shift to less-clustered communities over time, (Figure 4; ANOVA and Kruskal-Wallis contrasts, $P<0.05$ for NTI and NRI; Supplementary Table 1). In addition, we know of no outdoor air-sample communities that have been analyzed using molecular gene surveys, which contain Bacilli at such high relative abundance $(\sim 90 \%)$ as we observed here in early successional communities (Brodie et al., 2007; Bowers et al., 2009, 2011). Thus, in addition to the support for stochastic processes in early assembly, these data also simultaneously support a role for environmental selection at a potential trait level-rRNA operon copy number-in early succession. The forces acting on rRNA copy number maintenance are more complicated than a simple efficiency-growth rate 
1152
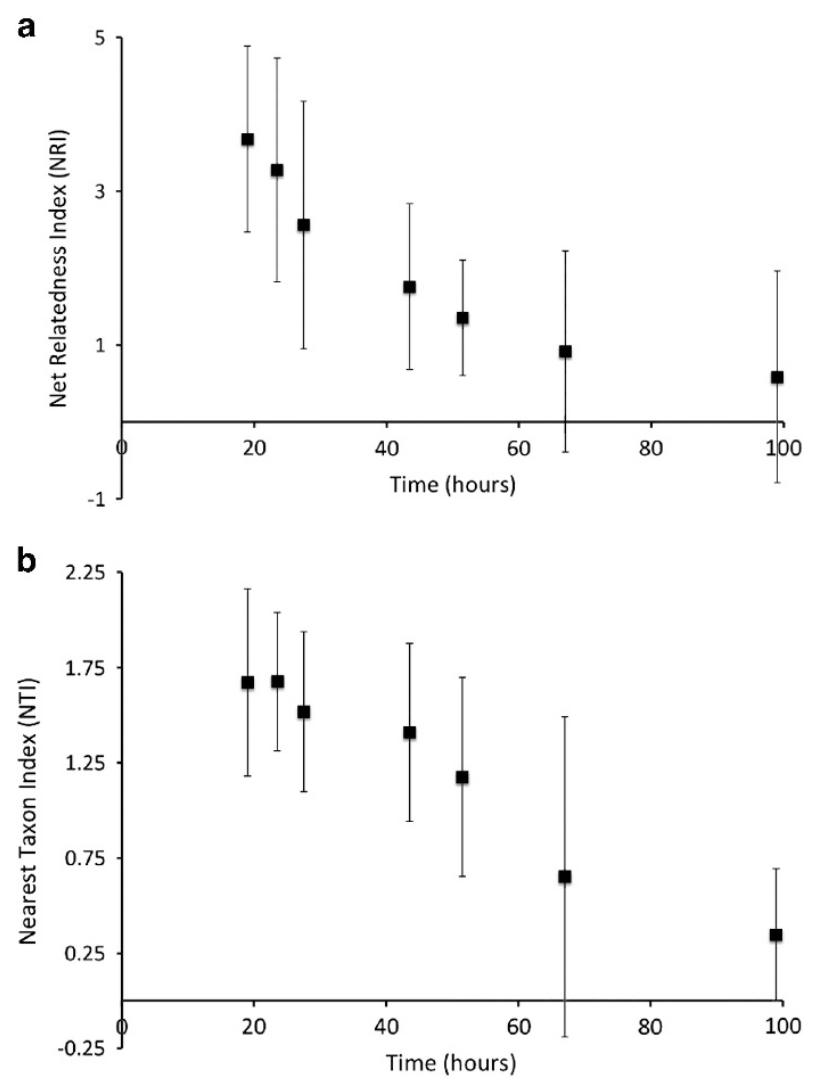

Figure 4 (a) Net Relatedness Index and (b) Nearest Taxon Index over successional time. Both indices show a significant decrease in phylogenetic clustering as communities assemble. For these analyses we used the Greengenes gg 13_5 tree that was trimmed in QIIME to contain only OTUs observed in this study. Bars represent s.d.

trade-off (Stevenson and Schmidt, 2004); however, more research will be needed to uncover the relevant evolutionary and ecological pressures on these operons.

Our data also reveal a significant increase in OTUrelated beta diversity-pairwise dissimilarity—over time (Figures 1a and b), which, combined with the relatively controlled environmental conditions, may lead to the hypothesis that later successional communities are more stochastically assembled. Although this hypothesis may arise at the taxonomic level, the trait-based data suggest that later successional communities are dominated by organisms with relatively low rRNA operon copy numbers. Thus, this low variance in mean aggregated copy number suggests that this trait may engender a selective advantage in the context of later successional communities, pointing to rRNA copy number as a fundamental trait in microbial life history strategies.

Later successional communities were also significantly overdispersed (less phylogenetically clustered) than earlier communities (Figure 4). Overdispersion patterns in phylogeny have been interpreted as support for the role of competition in community assembly (Webb, 2000; Kraft et al., 2007;
Violle et al., 2011). Stabilizing niche differences require density-dependent growth and thus may become increasingly important as community size (for example, number of individuals) increases (Chesson, 2000; HilleRisLambers et al., 2012). An alternative (but nonmutually exclusive) hypothesis is that successional time allowed for greater immigration of different species from the regional species pool, which resulted in the development of more phylogenetically diverse communities. However, while both dispersal and competition likely have roles in community assembly in this system, the strong trait convergence that we observed in the later successional communities (Figure 2) clearly supports the supposition that environmental selection is key in community assembly processes in these microcosms.

An important alternative hypothesis that could explain the patterns observed in this particular microcosm study is that the link between average copy number and successional stage may be due to oxygen availability, and because of the low diversity of microcosm communities, any trends in average copy number may be coincidental. Indeed, four dominant taxa: Bacillus (primarily aerobic), Enterobacteriales (facultative), Pseudomonadales (facultative) and Clostridia (anaerobic), all generally shift in dominance with advancing successional stage (Figure 3). To address this hypothesis, we examined trends in copy number in a suite of diverse successional systems that feature much higher levels of microbial diversity and vastly different environmental conditions: a salt marsh sediment primarysuccessional community (Dini-Andreote et al., 2015), a recently deglaciated Alaskan soil, and a secondary-successional burned soil from Colorado (Ferrenberg et al., 2013). In each case, we observed a significant decrease in average copy number with successional time (Figure 5, Kruskal-Wallis contrasts $P<0.05)$. The glacier chronosequence, sampled in a continuous manner, also revealed a significant relationship between rRNA copy number and successional time (linear regression, multiple $\left.R^{2}=0.4949, P<0.0001\right)$. Although a full metaanalysis is beyond the scope of this paper, it is clear that decreases in average rRNA operon copy number are a consistent feature of a diverse set of microbial successional communities.

In the microcosm study, we observed an increase in beta diversity as well as a decrease in phylogenetic clustering and weighted mean rRNA operon copy number during microbial community succession. The low variance in copy number both early and late in assembly supports the role of environmental selection in this microbial trait during succession, leading us to hypothesize that a larger metacommunity of low copy number organisms allowed for the divergence of community composition and simultaneous trait conversion. Thus, while a taxonomy or phylogeny-only approach would have led to hypotheses primarily focused on the role of 
a

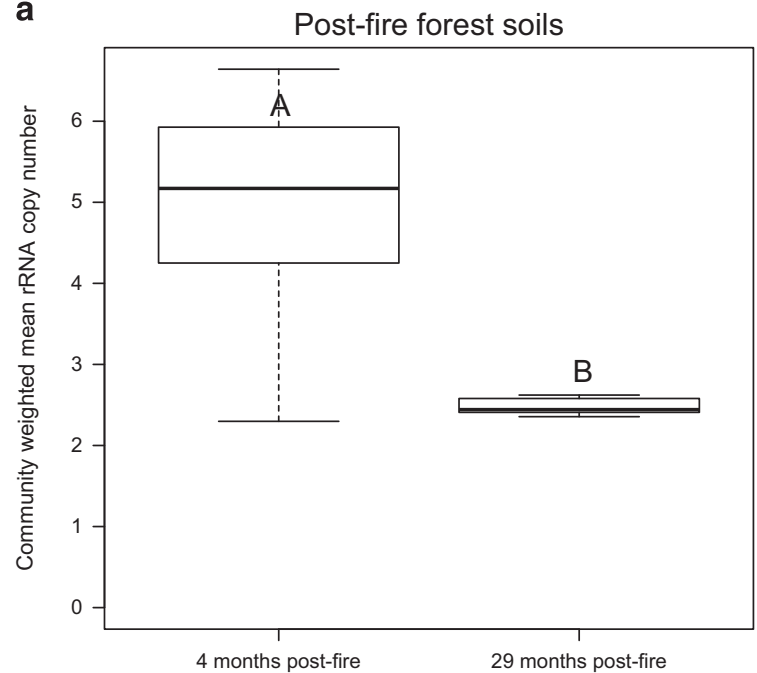

b

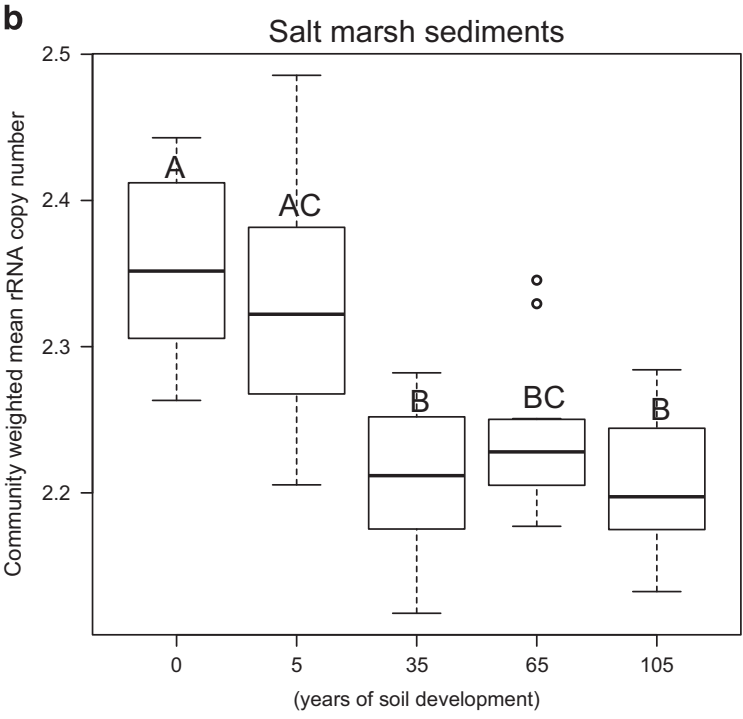

C

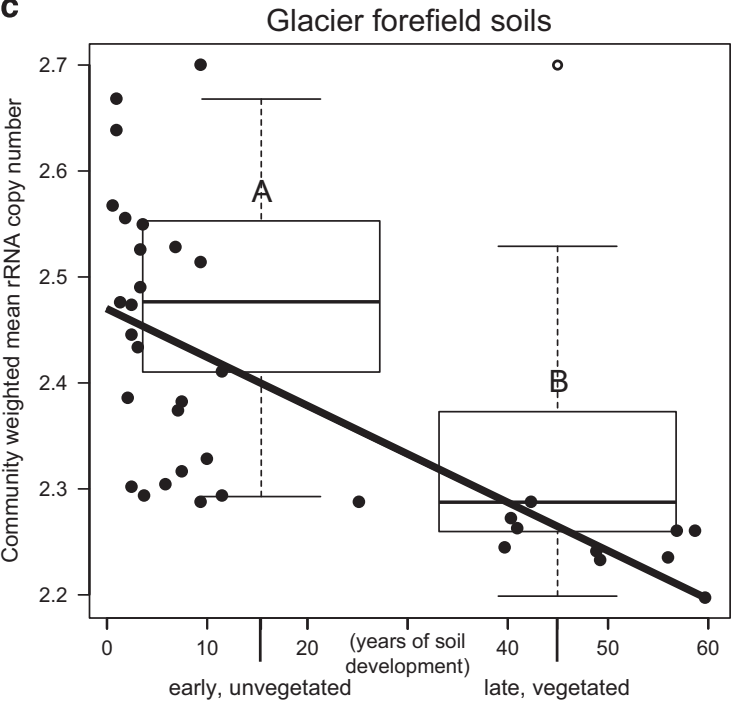

stochasticity in both early and late community development, patterns of trait dispersion support the importance of environmental selection over the course of succession. Interestingly, the three other systems examined did not reveal consistent successional trends in taxonomic dispersion, with the salt marsh study showing a decrease in dispersion and the soil sequences showing no change in beta diversity over the time period examined. The fact that all four chronosequences displayed consistent decreases in copy number despite stark differences in both environmental conditions and successional trajectories suggests copy number may be a core trait for bacteria underlying basic life history strategies that is generalizable across environments. We expect that other traits may similarly shift over the course of succession in a directional and predictive manner, but because such traits likely relate to more specific conditions of the environment, rRNA copy number is powerful in its apparent importance in assembly across systems.

Trait-based studies are also essential for understanding the implications of assembly processes for ecosystem function. The relationship between the traits that structure communities (that is, response traits) and those traits that affect the environment (that is, effect traits) is key to understanding the implications of community assembly for ecosystem processes (Allison, 2012; Ferrenberg et al., 2014; Knelman and Nemergut, 2014; Nemergut et al., 2014). For example, Nemergut et al. (2013) hypothesized that stochastic assembly processes could decouple community composition from environmental conditions, which could lead to unpredictable relationships between the environment and ecosystem processes as well as between biodiversity and ecosystem function (Knelman and Nemergut, 2014). Thus, a more trait-centric view on this and other assemblyfunction hypotheses is essential to predict and understand the impacts of environmental change on ecosystem processes (Lavorel and Grigulis, 2012; Evans and Wallenstein, 2014). Overall, our work supports the scaling of copy number from cells to populations and communities, suggesting that it may be a core trait that can lend insight into the ecological and evolutionary mechanisms driving patterns in microbial biodiversity across multiple levels of biological organization.

Figure 5 Boxplots and scatterplot showing a decrease in the mean weighted rRNA copy number over successional time for the three additional communities examined: a burned forest soil (a) (Ferrenberg et al., 2013); a salt marsh sediment chronosequence (b) (Dini-Andreote et al., 2015); and a glacier forefield chronosequence (c), which included linear regression analysis (multiple $R^{2}=0.4949, P<0.0001$ ). Copy number was estimated using PICRUSt (Langille et al., 2013) and weighted values were obtained by multiplying rRNA copy numbers by relative abundance for a given OTU, and summing weighted averages across a given sample. 


\section{Conflict of Interest}

The authors declare no conflict of interest.

\section{Acknowledgements}

We thank Sean O’Neill for laboratory assistance, Emily Graham for insightful discussions and two anonymous reviewers whose comments greatly improved the quality of this paper. This work was supported in part by the National Science Foundation of the USA through grants to DRN, SKS, and BM (DEB-1258160) and a graduate research fellowship to JEK (DGE 1144083).

\section{References}

Ackerly DD, Cornwell WK. (2007). A trait-based approach to community assembly: partitioning of species trait values into within- and among-community components. Ecol Lett 10: 135-145.

Allison SD. (2012). A trait-based approach for modelling microbial litter decomposition. Ecol Lett 15: 1058-1070.

Anderson MJ. (2001). A new method for non-parametric multivariate analysis of variance. Austral Ecol 26: $32-46$.

Anderson MJ. (2006). Distance-based tests for homogeneity of multivariate dispersions. Biometrics 62: 245-253.

Andersson MGI, Berga M, Lindström ES, Langenheder S. (2014). The spatial structure of bacterial communities is influenced by historical environmental conditions. Ecology 95: 1134-1140.

Bowers RM, Lauber CL, Wiedinmyer C, Hamady M, Hallar AG, Fall R et al. (2009). Characterization of airborne microbial communities at a high-elevation site and their potential to act as atmospheric ice nuclei. Appl Environ Microbiol 75: 5121-5130.

Bowers RM, McLetchie S, Knight R, Fierer N. (2011). Spatial variability in airborne bacterial communities across land-use types and their relationship to the bacterial communities of potential source environments. ISME J 5: 601-612.

Brodie EL, DeSantis TZ, Parker JPM, Zubietta IX, Piceno YM, Andersen GL. (2007). Urban aerosols harbor diverse and dynamic bacterial populations. Proc Natl Acad Sci USA 104: 299-304.

Burke C, Steinberg P, Rusch D, Kjelleberg S, Thomas T. (2011). Bacterial community assembly based on functional genes rather than species. Proc Natl Acad Sci USA 108: 14288-14293.

Caporaso JG, Kuczynski J, Stombaugh J, Bittinger K, Bushman FD, Costello EK et al. (2010). QIIME allows analysis of high-throughput community sequencing data. Nat Methods 7: 335-336.

Caporaso JG, Lauber CL, Walters WA, Berg-Lyons D, Huntley J, Fierer N et al. (2012). Ultra-high-throughput microbial community analysis on the Illumina HiSeq and MiSeq platforms. ISME J 6: 1621-1624.

Chapin FS, Walker LR, Fastie CL, Sharman LC. (1994). Mechanisms of primary succession following deglaciation at Glacier Bay, Alaska. Ecol Monogr 64: 149-175.

Chase JM. (2003). Community assembly: when should history matter? Oecologia 136: 489-498.
Chase JM. (2010). Stochastic community assembly causes higher biodiversity in more productive environments. Science 328: 1388-1391.

Chesson P. (2000). Mechanisms of maintenance of species diversity. Annu Rev Ecol Syst 31: 343-366.

Condon C, Liveris D, Squires C, Schwartz I, Squires CL. (1995). rRNA operon multiplicity in Escherichia coli and the physiological implications of rrn inactivation. J Bacteriol 177: 4152-4156.

DeAngelis KM, Pold G, Topçuoğlu BD, van Diepen LTA, Varney RM, Blanchard JL et al. (2015). Long-term forest soil warming alters microbial communities in temperate forest soils. Front Microbiol 6: 104.

DeSantis TZ, Hugenholtz P, Larsen N, Rojas M, Brodie EL, Keller $\mathrm{K}$ et al. (2006). Greengenes, a chimerachecked 16S rRNA gene database and workbench compatible with ARB. Appl Environ Microbiol 72: 5069-5072.

Dini-Andreote F, Stegen JC, van Elsas JD, Salles JF. (2015). Disentangling mechanisms that mediate the balance between stochastic and deterministic processes in microbial succession. Proc Natl Acad Sci USA 112: E1326-E1332.

Edgar RC. (2010). Search and clustering orders of magnitude faster than BLAST. Bioinformatics 26: 2460-2461.

Evans SE, Wallenstein MD. (2014). Climate change alters ecological strategies of soil bacteria. Ecol Lett 17: 155-164.

Ferrenberg S, Knelman JE, Jones JM, Beals SC, Bowman WD, Nemergut DR. (2014). Soil bacterial community structure remains stable over a 5-year chronosequence of insect-induced tree mortality. Front Microbiol 5: 681.

Ferrenberg S, O’Neill SP, Knelman JE, Todd B, Duggan S, Bradley D et al. (2013). Changes in assembly processes in soil bacterial communities following a wildfire disturbance. ISME J 7: 1102-1111.

Fierer N, Barberán A, Laughlin DC. (2014). Seeing the forest for the genes: using metagenomics to infer the aggregated traits of microbial communities. Front Microbiol 5: 614.

Fierer N, Bradford MA, Jackson RB. (2007). Toward an ecological classification of soil bacteria. Ecology 88: 1354-1364.

Fierer N, Hamady M, Lauber CL, Knight R. (2008). The influence of sex, handedness, and washing on the diversity of hand surface bacteria. Proc Natl Acad Sci USA 105: 17994-17999.

Fukami T, Dickie IA, Paula Wilkie J, Paulus BC, Park D, Roberts A et al. (2010). Assembly history dictates ecosystem functioning: evidence from wood decomposer communities. Ecol Lett 13: 675-684.

Fukami T, Martijn Bezemer T, Mortimer SR, van der Putten WH. (2005). Species divergence and trait convergence in experimental plant community assembly. Ecol Lett 8: $1283-1290$.

Garnier E, Cortez J, Billès G, Navas M-L, Roumet C, Debussche $\mathrm{M}$ et al. (2004). Plant functional markers capture ecosystem properties during secondary succession. Ecology 85: 2630-2637.

Garnier E, Lavorel S, Ansquer P, Castro H, Cruz P, Dolezal J et al. (2007). Assessing the effects of land-use change on plant traits, communities and ecosystem functioning in grasslands: a standardized methodology and lessons from an application to 11 European sites. Ann Bot 99: 967-985. 
Goberna M, Navarro-Cano JA, Valiente-Banuet A, García C, Verdú M. (2014). Abiotic stress tolerance and competition-related traits underlie phylogenetic clustering in soil bacterial communities. Ecol Lett 17: 1191-1201.

Green JL, Bohannan BJM, Whitaker RJ. (2008). Microbial biogeography: from taxonomy to traits. Science 320: 1039-1043.

Grime JP. (1977). Evidence for the existence of three primary strategies in plants and its relevance to ecological and evolutionary theory. Am Nat 111: 1169-1194.

Hanson CA, Fuhrman JA, Horner-Devine MC, Martiny JBH. (2012). Beyond biogeographic patterns: processes shaping the microbial landscape. Nat Rev Microbiol 10: $497-506$.

HilleRisLambers J, Adler PB, Harpole WS, Levine JM, Mayfield MM. (2012). Rethinking community assembly through the lens of coexistence theory. Annu Rev Ecol Evol Syst 43: 227-248.

Kardol P, Souza L, Classen AT. (2013). Resource availability mediates the importance of priority effects in plant community assembly and ecosystem function. Oikos 122: 84-94.

Keddy P, Twolan-Strutt L, Shipley B. (1997). Experimental evidence that interspecific competitive asymmetry increases with soil productivity. Oikos 80: 253-256.

Kembel SW, Cowan PD, Helmus MR, Cornwell WK, Morlon H, Ackerly DD et al. (2010). Picante: R tools for integrating phylogenies and ecology. Bioinformatics 26: $1463-1464$.

Klappenbach JA, Dunbar JM, Schmidt TM. (2000). rRNA operon copy number reflects ecological strategies of bacteria. Appl Environ Microbiol 66: 1328-1333.

Klappenbach JA, Saxman PR, Cole JR, Schmidt TM. (2001). rrndb: the ribosomal RNA operon copy number database. Nucleic Acids Res 29: 181-184.

Knelman JE, Legg TM, O'Neill SP, Washenberger CL, González A, Cleveland CC et al. (2012). Bacterial community structure and function change in association with colonizer plants during early primary succession in a glacier forefield. Soil Biol Biochem 46: 172-180.

Knelman JE, Nemergut DR. (2014). Changes in community assembly may shift the relationship between biodiversity and ecosystem function. Front Microbiol 5: 424.

Knelman JE, Schmidt SK, Lynch RC, Darcy JL, Castle SC, Cleveland CC et al. (2014). Nutrient addition dramatically accelerates microbial community succession. PLoS One 9: e102609.

Koeppel AF, Wu M. (2014). Species matter: the role of competition in the assembly of congeneric bacteria. ISME J 8: 531-540.

Kraft NJB, Cornwell WK, Webb CO, Ackerly DD. (2007). Trait evolution, community assembly, and the phylogenetic structure of ecological communities. Am Nat 170: 271-283.

Krause S, Le Roux X, Niklaus PA, Van Bodegom PM, Lennon JT, Bertilsson S et al. (2014). Trait-based approaches for understanding microbial biodiversity and ecosystem functioning. Front Microbiol 5: 251.

Langenheder S, Berga M, Östman Ö, Székely AJ. (2012). Temporal variation of $\beta$-diversity and assembly mechanisms in a bacterial metacommunity. ISME J 6: 1107-1114.

Langenheder S, Székely AJ. (2011). Species sorting and neutral processes are both important during the initial assembly of bacterial communities. ISME J 5: 1086-1094.

Langille MGI, Zaneveld J, Caporaso JG, McDonald D, Knights D, Reyes JA et al. (2013). Predictive functional profiling of microbial communities using 16S rRNA marker gene sequences. Nat Biotechnol 31: 814-821.

Lauro FM, McDougald D, Thomas T, Williams TJ, Egan S, Rice S et al. (2009). The genomic basis of trophic strategy in marine bacteria. Proc Natl Acad Sci USA 106: 15527-15533.

Lavorel S, Grigulis K. (2012). How fundamental plant functional trait relationships scale-up to trade-offs and synergies in ecosystem services. I Ecol 100: 128-140.

Lennon JT, Aanderud ZT, Lehmkuhl BK, Schoolmaster DR. (2012). Mapping the niche space of soil microorganisms using taxonomy and traits. Ecology 93: 1867-1879.

Lindström ES, Langenheder S. (2012). Local and regional factors influencing bacterial community assembly. Environ Microbiol Rep 4: 1-9.

Lozupone C, Hamady M, Knight R. (2006). UniFrac - an online tool for comparing microbial community diversity in a phylogenetic context. BMC Bioinformatics 7: 371.

Matthews JA. (1992). The Ecology of Recently-Deglaciated Terrain: A Geoecological Approach to Glacier Forelands and Primary Succession. Cambridge University Press: Cambridge, UK.

Nemergut DR, Schmidt SK, Fukami T, O’Neill SP, Bilinski TM, Stanish LF et al. (2013). Patterns and processes of microbial community assembly. Microbiol Mol Biol Rev 77: 342-356.

Nemergut DR, Shade A, Violle C. (2014). When, where and how does microbial community composition matter? Front Microbiol 5: 497.

Ofiteru ID, Lunn M, Curtis TP, Wells GF, Criddle CS, Francis CA et al. (2010). Combined niche and neutral effects in a microbial wastewater treatment community. Proc Natl Acad Sci USA 107: 15345-15350.

Oksanen J, Blanchet FG, Kindt R, Legendre P, Minchin P, O'Hara RB et al. (2013) Vegan: Community Ecology Package http://CRAN.R-project.org/package=vegan.

R Development Core Team (2013). R: A Language and Environment For Statistical Computing. Vienna, Austria: R Foundation for Statistical Computing. http://www.R-project.org.

Reeder J, Knight R. (2010). Rapid denoising of pyrosequencing amplicon data: exploiting the rank-abundance distribution. Nat Methods 7: 668-669.

Reznick D, Bryant MJ, Bashey F. (2002). r- and K-selection revisted: The role of population regulation in lifehistory evolution. Ecology 83: 1509-1520.

Shipley B, Vile D, Garnier E. (2006). From plant traits to plant communities: a statistical mechanistic approach to biodiversity. Science 314: 812-814.

Shrestha PM, Noll M, Liesack W. (2007). Phylogenetic identity, growth-response time and rRNA operon copy number of soil bacteria indicate different stages of community succession. Environ Microbiol 9: 2464-2474.

Sloan WT, Lunn M, Woodcock S, Head IM, Nee S, Curtis TP. (2006). Quantifying the roles of immigration and chance in shaping prokaryote community structure. Environ Microbiol 8: 732-740.

Stegen JC, Lin X, Fredrickson JK, Chen X, Kennedy DW, Murray CJ et al. (2013). Quantifying community assembly processes and identifying features that impose them. ISME J 7: 2069-2079.

Stegen JC, Lin X, Konopka AE, Fredrickson JK. (2012). Stochastic and deterministic assembly processes in subsurface microbial communities. ISME J 6: 1653-1664. 
Stevenson BS, Schmidt TM. (2004). Life history implications of rRNA gene copy number in Escherichia coli. Appl Environ Microbiol 70: 6670-6677.

Violle C, Navas M-L, Vile D, Kazakou E, Fortunel C, Hummel I et al. (2007). Let the concept of trait be functional!. Oikos 116: 882-892.

Violle C, Nemergut DR, Pu Z, Jiang L. (2011). Phylogenetic limiting similarity and competitive exclusion. Ecol Lett 14: 782-787.

Walker LR, del Moral R. (2003). Primary Succession and Ecosystem Rehabilitation. Cambridge University Press: Cambridge, UK.

Webb CO, Ackerly DD, Kembel SW. (2008). Phylocom: software for the analysis of phylogenetic community structure and trait evolution. Bioinformatics 24: 2098-2100.

Webb CO. (2000). Exploring the Phylogenetic structure of ecological communities: an example for rain forest trees. Am Nat 156: 145-155.

Webb CT, Hoeting JA, Ames GM, Pyne MI, LeRoy Poff N. (2010). A structured and dynamic framework to advance traits-based theory and prediction in ecology. Ecol Lett 13: 267-283.
Yano K, Wada T, Suzuki S, Tagami K, Matsumoto T, Shiwa Y et al. (2013). Multiple rRNA operons are essential for efficient cell growth and sporulation as well as outgrowth in Bacillus subtilis. Microbiology 159: 2225-2236.

Zhou J, Deng Y, Zhang P, Xue K, Liang Y, Nostrand JDV et al. (2014). Stochasticity, succession, and environmental perturbations in a fluidic ecosystem. Proc Natl Acad Sci USA 111: E836-E845.

(c) (1)(2) This work is licensed under a Creative (c) ${ }_{\mathrm{BY}} \mathrm{NC}$ SA Commons Attribution-NonCommercialShareAlike 4.0 International License. The images or other third party material in this article are included in the article's Creative Commons license, unless indicated otherwise in the credit line; if the material is not included under the Creative Commons license, users will need to obtain permission from the license holder to reproduce the material. To view a copy of this license, visit http:/creativecommons.org/ licenses/by-nc-sa/4.0/

Supplementary Information accompanies this paper on The ISME Journal website (http://www.nature.com/ismej) 